\title{
Noni (Morinda citrifolia Linn.) fruit juice attenuates the rewarding effect of ethanol in conditioned place preference in mice
}

\author{
Vijayapandi PANDY and Yasmin KHAN \\ Department of Pharmacology, Faculty of Medicine, University of Malaya, 50603 Kuala Lumpur, Malaysia
}

\begin{abstract}
Morinda citrifolia L. commonly known as noni or Indian mulberry belongs to the family Rubiaceae. Noni fruit juice has recently become a very popular remedy for the treatment of several diseases, including psychiatric disorders. This study aimed to investigate the anticraving effect of Tahitian Noni® Juice (TNJ) against ethanol seeking behavior in ICR male mice using the conditioned place preference (CPP) test. The CPP procedure consisted of four phases: preconditioning, conditioning, extinction, and reinstatement. During conditioning, intraperitoneal (i.p.) injections of ethanol ( $2 \mathrm{~g} / \mathrm{kg}$ body weight (bw)) and normal saline $(10 \mathrm{ml} / \mathrm{kg} \mathrm{bw}$ ) were given on alternate days for 12 days. Then, the animals were subjected to extinction trials for the next 12 days to weaken CPP. Finally, CPP was reinstated in the extinguished animals by a single low-dose priming injection of ethanol $(0.4 \mathrm{~g} / \mathrm{kg}$ bw, i.p.). The effect of TNJ (as a source of drinking water) on different phases of ethanol CPP in mice was studied. TNJ-treated mice showed a significant reduction in ethanol seeking behavior in the CPP test. The reference drug, acamprosate (ACAM) also showed a similar effect in the CPP test. The outcome of this study suggests that TNJ is effective in attenuating ethanol craving in mice and could be utilized for the treatment of alcohol dependence. Further clinical studies in this direction are warranted to support the present preclinical findings.
\end{abstract}

Key words: acamprosate, alcohol, conditioned place preference, dependence, noni juice

\section{Introduction}

Dependence on alcohol or any other drug abuse can affect all day-to-day normal activities of the user. Drug abuse patients not only spoil their health but also damage their social life (e.g., loss of their families, friends, and jobs and indulging in deviant behavior). Drug dependency is characterized as uncontrolled drug use, longterm relapses, and a powerful desire for drug use that can happen even after a long period of abstinence [2]. Regarding pharmacological treatment strategies for drug dependence, some recent studies focused on and highlighted the efficacies of medicinal herbs in combating many kinds of drug dependence, including alcohol, cocaine, nicotine, methamphetamine, and opioid dependence $[20,21]$.

Acamprosate (calcium acetylhomotaurinate) is a putative anticraving drug used clinically to treat alcohol dependence. Its mechanism of action is not completely clear, but evidence suggests that the anticraving effect of acamprosate is mediated by reducing the pathologic glutamatergic hyperactivity that occurs during protracted withdrawal from alcohol [3]. Animal studies revealed that acamprosate can reduce ethanol consumption, ethanol withdrawal severity, and relapse [10, 16, 34]. In clinical studies, acamprosate was similarly found to be

(Received 15 February 2016 / Accepted 26 May 2016 / Published online in J-STAGE 21 June 2016)

Address corresponding: V. Pandy, Department of Pharmacology, Faculty of Medicine, University of Malaya, 50603 Kuala Lumpur, Malaysia

Yasmin Khan and Vijayapandi Pandy contributed equally to this project and should be considered co-first authors.

(C)2016 Japanese Association for Laboratory Animal Science 
effective in prolonging abstinence and reducing the rate of relapse [16].

Morinda citrifolia $\mathrm{L}$ is a small tropical woody evergreen shrub native to Southeast Asia. It was initially cultivated by Polynesians in Tahiti, the Marquesas, and Hawaiian Islands. Its' cultivation is now extended to the South Pacific, Caribbean, South America, and West Indies [33]. Recently, noni juice attained wide attention due to its various health benefits in treating cancer and its associated pain, nausea, vomiting, arthritis, diabetes, and CNS disorders such as anxiety, depression, and psychosis $[29,33]$. Noni juice is obtained from the ripe fruit of the noni and is commercially available as a health drink, herbal drink, and food supplement. Consumption of noni juice has been approved by the Scientific Committee on Food of the European Commission [4]. The commercial value of noni products is constantly increasing, which is evident from the number of US patents filed that make use of Morinda citrifolia. To date, 119 patents related to Morinda citrifolia have been registered with the US Patent and Trademark Office [36].

The different parts of the noni have been used in herbal medicine for many years to treat cancer; cardiovascular illness (i.e., high blood pressure, heart disease, atherosclerosis); mental illnesses such as anxiety, depression, and psychosis; diabetes; arthritis; muscle aches and pains; sprains; menstrual difficulties; gastric ulcers; senility; poor digestion; headaches; and drug addiction [32, 37]. There is, however, a growing belief in the efficacy of noni in treatment of various drugs of abuse as described in the website "Regenerative Nutrition," and we have had personal communication with an Ayurvedic practitioner who claims to have success in treating various drugs of abuse with noni. Scientific evidences for the claim of being able to treat heroin addiction has been recently reported by our research group [25]. As a continuation of our recent report, this study was undertaken to examine the effect of noni juice on ethanolseeking behavior in mice using the conditioned place preference (CPP) test.

The CPP paradigm is a widely used and validated animal model for study of the rewarding effects of a wide variety of self-administered drugs, including ethanol [35]. It can also be used to model the relapse of drugseeking behavior after a period of drug withdrawal or abstinence; in such instances, exposure to low doses of the addictive substance or administration of mild stress can induce reinstatement of otherwise "extinguished"
CPPs [1]. The present study investigated the effect of Tahitian Noni Juice (TNJ) on the rewarding properties of ethanol in acquisition, extinction, and reinstatement of ethanol CPP in mice.

\section{Materials and Methods}

\section{Animals}

Male ICR mice (UKM, Kuala Lumpur, Malaysia) weighing 25 to $30 \mathrm{~g}$ (7-8 weeks of age) were housed in polycarbonate cages for two weeks before use. All animals were housed in groups $(\mathrm{n}=4-5$ per cage) and were maintained with a $12 \mathrm{~h}$ light/dark cycle (lights off at 19:00), a temperature of 20 to $23^{\circ} \mathrm{C}$, and a humidity of 40 to $60 \%$ with free access to food and purified water. The animals were acclimatized to the housing unit and handled for 7 days before the start of the experimental session. Utmost care was taken to minimize animal suffering. All experimental protocols were approved by the Institutional Animal Care and Use Committee, Faculty of Medicine, University of Malaya, Kuala Lumpur (Approval No. 2013-12-03/PHAR/R/VP), and care of the animals was performed according to the Guide for the Care and Use of Laboratory Animals published by National Research Council of the National Academics of Sciences, Engineering, and Medicine, USA ("Guide for the Care and Use of Laboratory Animals," Eighth Edition) [15].

\section{Drugs}

Ethanol $(10 \% \mathrm{v} / \mathrm{v})$ was obtained by dilution of $95 \%$ $\mathrm{v} / \mathrm{v}$ ethanol (Copens Scientific, Malaysia) in sterile water for injection. Ethanol and normal saline were administered intraperitoneally. Acamprosate (ACAM; SigmaAldrich, USA) solution was prepared using $0.5 \% \mathrm{w} / \mathrm{v}$ sodium carboxymethyl cellulose (CMC) at a dose of 300 $\mathrm{mg} / \mathrm{kg}$ body weight (bw), and it was administered orally $1 \mathrm{~h}$ prior to behavioral testing. The drug solution was prepared fresh prior to the start of the experiment and administered at a constant volume of $10 \mathrm{ml} / \mathrm{kg}$ bw of the animal. The commercially available noni fruit juice brand, TNJ, was provided from local suppliers in Kuala Lumpur, Malaysia. In the TNJ-treated group, TNJ was made available to the animals as a source of drinking water throughout the study period, with plain water being provided for $1 \mathrm{~h}$ daily. The average consumption of TNJ was calculated to be $18.4 \mathrm{ml} / 100 \mathrm{~g}$ bw/day. In our recent publication, we reported that the average amounts 
of TNJ consumed at 10,30 , and $100 \% \mathrm{v} / \mathrm{v}$ were $\sim 6,10$, and $13 \mathrm{ml} / 100 \mathrm{~g} /$ day, respectively [29].

\section{Conditioned place preference apparatus}

Place preference conditioning was performed as described elsewhere [7, 19] with minor modifications. The CPP test box was made of plexiglass $(45(\mathrm{~L}) \times 15(\mathrm{~W}) \times 15(\mathrm{H})$ $\mathrm{cm})$ and was divided into two equal-sized compartments $(20 \times 15 \times 15 \mathrm{~cm})$ by insertion of two removable plexiglass partitions; the two compartments were separated by a small gray zone $(5 \times 15 \times 15 \mathrm{~cm})$ in the middle of the chamber. The two compartments had distinct visual and tactile cues: the compartment on one side had black walls with white horizontal stripes and had white wire mesh on the floor (white compartment), while the compartment on the other side had white walls with vertical black lines and a smooth black plexiglass floor (black compartment). Matched removable partitions were used to close-off each compartment. Transparent plexiglass lids allowed observation of animal behavior on a computer connected to a Logitech HD Webcam placed above the apparatus. Mouse behavior was recorded on a computer and later scored by an experimenter who was blind to each subject's treatment status.

\section{CPP procedure and experimental design}

The CPP methodology was divided into six distinct phases: habituation, preconditioning/baseline, conditioning, post-conditioning, extinction, and reinstatement. The experimental design is shown in Fig. 1. All tests were conducted during the same time period of each day (08:00-15:00 h).

\section{Habituation and preconditioning}

After 3 days habituation of the mice in the CPP box, each mouse was placed in the central gray-painted compartment of the CPP box for $5 \mathrm{~min}$, both removable partitions were lifted, and the animals were allowed to explore freely both compartments for $15 \mathrm{~min}$. The procedure the next day (Day 0) was conducted in the identical manner to habituation except that the time spent in each compartment was recorded and served as the preconditioning baseline. In every trial, animals were immediately returned to their home cages following testing. On the preconditioning day, in order to avoid preference for either of the two compartments, the innate preference of each animal was determined as described previously [21]. Any mouse that exhibited a strong unconditioned aversion $(<33 \%$ of the session time spent in one side of the apparatus, i.e., $300 \mathrm{~s}$ ) or preference $(>66 \%$ of the session time spent in one side of the apparatus, i.e., 600 s) for either compartment was removed from the study. In this study, the white and black compartments were paired with ethanol and saline, respectively, as described elsewhere [21].

\section{Conditioning}

During the conditioning phase (Day 1-Day 12), each mouse ( $\mathrm{n}=9$ /group) received ethanol and saline on alternate days in alternate compartments (white and black) before being confined to the respective compartments for 12 days. A mouse placed in the white compartment with a white mesh base received intraperitoneal injections of ethanol, whereas in the black compartment with a polished black surface, the mouse was injected with normal saline. The test groups (vehicle, TNJ, and ACAM) received ethanol injections ( $2 \mathrm{~g} / \mathrm{kg}$ bw, i.p.) on Days 1 , $3,5,7,9$, and 11 and saline ( $10 \mathrm{ml} / \mathrm{kg}$ bw, i.p.) injections on Days 2, 4, 6, 8, 10, and 12 of the conditioning phase. The saline control group received saline injections in both compartments on both odd and even days of the 12-day conditioning. After each injection (ethanol or saline), the mice were immediately confined to the respective conditioning compartment for $30 \mathrm{~min}$, and then the animals were returned to their home cages. The postconditioning test was performed on Day 14 (48 h following the last conditioning session). On the post-conditioning test day, the mice in an ethanol-free state were placed in the central gray compartment for $5 \mathrm{~min}$, both partitions were lifted, and the animals were allowed to move freely for $15 \mathrm{~min}$. The time spent in each compartment during the 15 -min session was recorded. A conditioning score in seconds was determined by subtracting the time spent in the white compartment from the time spent in the black compartment.

\section{Effect of TNJ on the rewarding properties of ethanol in different phases of the CPP test}

To study the effect of TNJ on the rewarding properties of ethanol, the TNJ-treated mice were tested for their preference regarding the black and white compartments on Day 14 (post-conditioning test), Days 15-26 (extinction tests), and Day 28 (reinstatement test). The reference drug ACAM-treated mice were similarly tested.

After 12 days of conditioning, animals were allowed to rest on the $13^{\text {th }}$ day. The post-conditioning test was 


\section{Experimental Timeline}

\section{Acquisition}

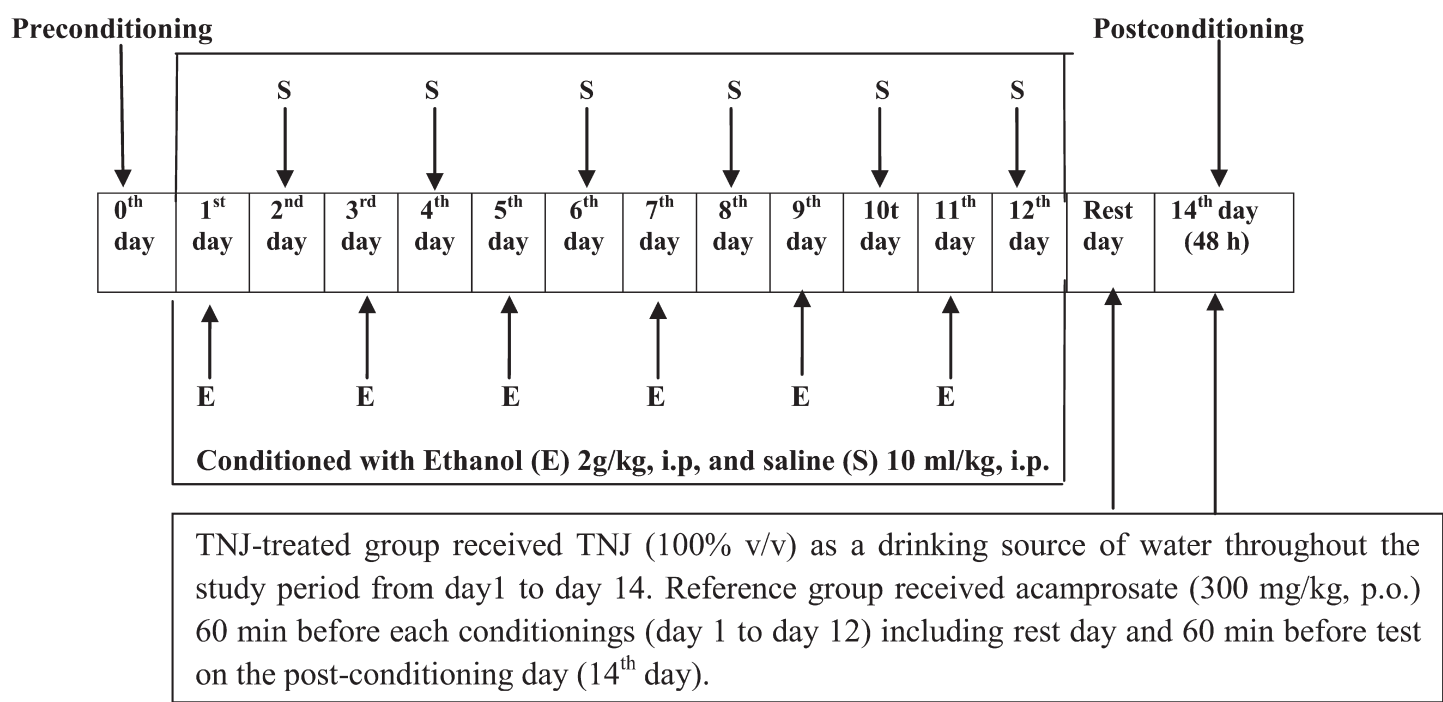

\section{Extinction and Reinstatement}

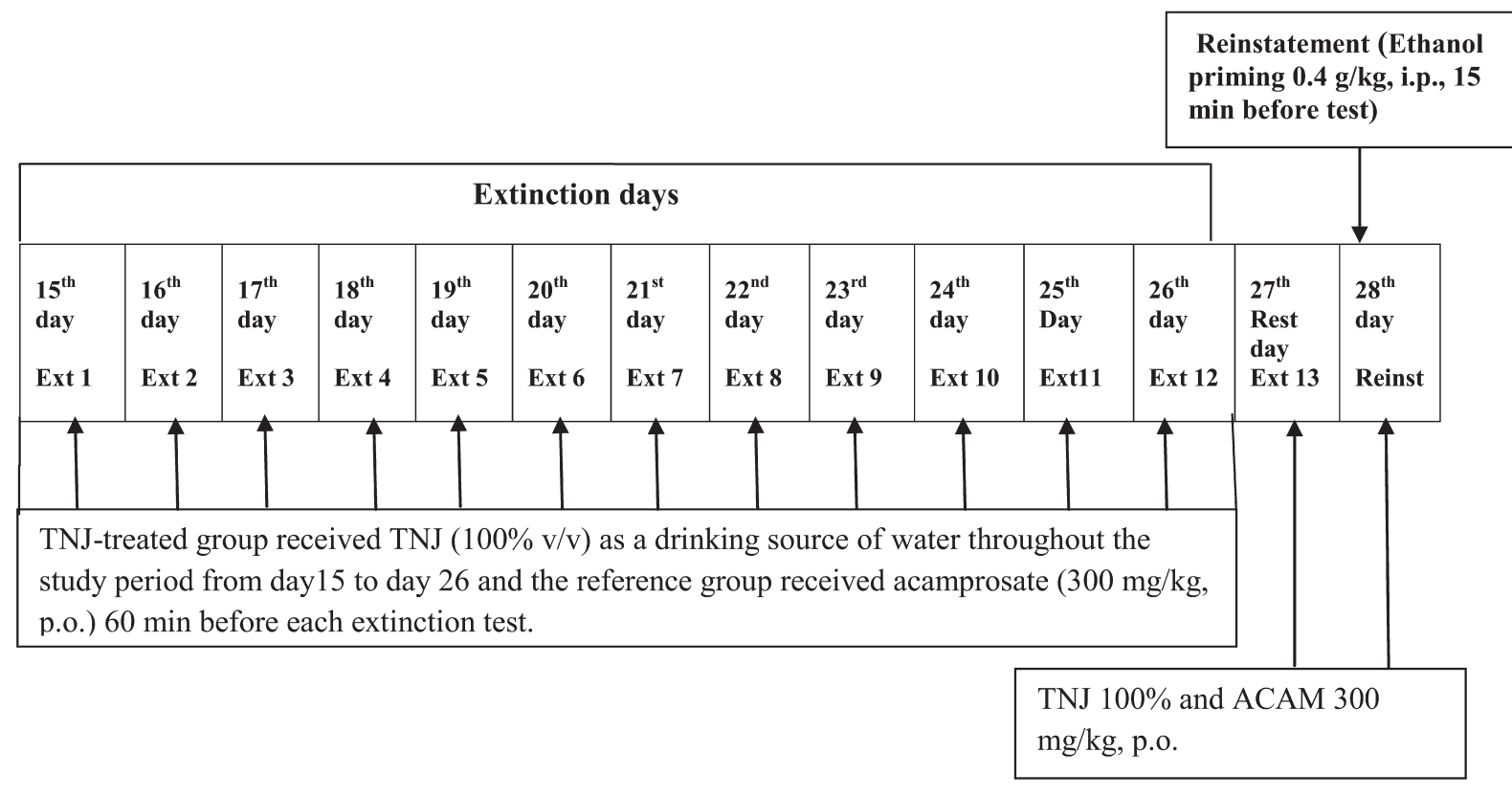

Fig. 1. Experimental timeline.

performed on Day 14. Beginning the day after the postconditioning test, extinction tests were carried out for 12 days (Day 15 to Day 26). On each extinction day, the test mice ( $\mathrm{n}=7-9$ / group) were exposed individually to the apparatus for 15 min with free access to both compartments. The time spent by the animals in each compartment was recorded for $15 \mathrm{~min}$. No ethanol or saline injections were given to the animals during the extinction phase of the study. Extinction testing was performed in all treatment groups (saline, vehicle, TNJ, and ACAM) for 12 days (Day 15 to Day 26).

One day after the last extinction session (27 th day), the mice were allowed to rest (not subjected to a CPP test). The next day ( $28^{\text {th }}$ day), the mice received a low- 


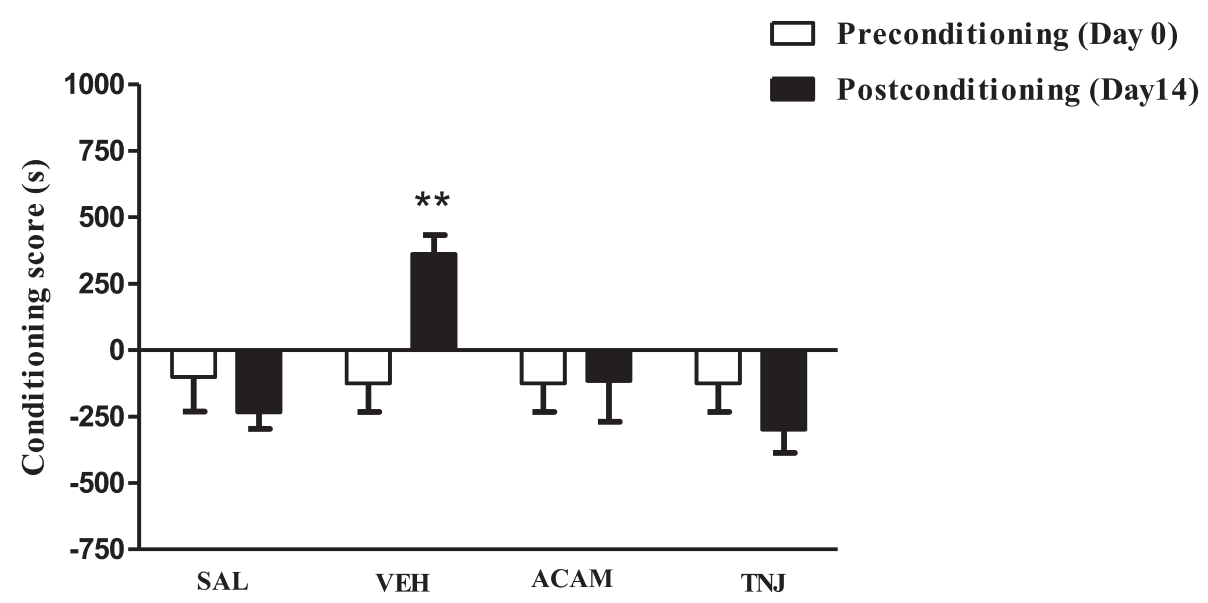

Fig. 2. Effect of TNJ and ACAM on the acquisition of ethanol CPP in mice. Data are expressed as the mean difference between the times spent in the compartment paired with ethanol and the times spent in the compartment paired with saline ( $n=9$ /group). There was a significant difference $(* * P<0.01)$ between the preconditioning and post-conditioning results; when not indicated, the differences were not statistically significant.

dose ethanol priming injection $(0.4 \mathrm{~g} / \mathrm{kg}$ bw, i.p. $)$ or saline $(10 \mathrm{ml} / \mathrm{kg}$ bw, i.p). The TNJ-treated group continued drinking TNJ as described earlier, while the other reference group received ACAM (300 mg/kg bw) per os (p.o.) $60 \mathrm{~min}$ before a low-dose ethanol priming injection. Fifteen minutes after the ethanol priming injection, the mice were subjected to reinstatement testing in which the mice were freely allowed to explore both compartments for $15 \mathrm{~min}$. The time spent in each compartment was measured.

\section{Statistical analysis}

All results are expressed as the mean $\pm \mathrm{SEM}$. The CPP results were analyzed using two-way analysis of variance (ANOVA) followed by post hoc multiple comparisons using the Bonferroni test and one-way ANOVA followed by a post hoc Newman-Keuls multiple comparison test. Statistical significance was set as $P<0.05$.

\section{Results}

Effect of TNJ on the rewarding properties of ethanol in different phases of the CPP test

The effect of TNJ and ACAM on the rewarding properties of ethanol in the ethanol CPP test on the postconditioning day (Day 14) is presented in Fig. 2. The ANOVA results revealed significant effects of group $[F$ $(3,64)=3.769 ; P<0.05]$ and group $\times$ trial interaction $[F$ $(3,64)=4.000 ; P<0.05]$. The Bonferroni test revealed that the conditioning score of the vehicle-treated group on the post-conditioning day was significantly $(P<0.01)$ increased when compared with that on the preconditioning day. However, the conditioning scores on the postconditioning day were not altered in TNJ- and ACAMtreated groups, which implies that TNJ and ACAM had anticraving effects.

Moreover, the ethanol-seeking behaviors of the TNJand ACAM- treated groups were compared with that of the vehicle-treated group during the extinction phase of the ethanol CPP and are depicted in Fig. 3. The ANOVA results revealed significant effects of group $[\mathrm{F}(3,151)=$ 33.48; $P<0.0001]$ and group $\times$ trial interaction $[F(15$, $151)=4.900 ; P<0.0001]$. A separate one-way ANOVA on the data from each extinction trial revealed that there were significant differences in conditioning score on extinction Day $15[\mathrm{~F}(3,25)=57.58, P<0.0001]$, Day $17[(3,25)=12.23, P<0.0001]$, and Day $19[(3,25)=$ 19.92, $P<0.0001]$. The vehicle control (VEH) group showed a marked preference for the ethanol-paired compartment from Day 15 to Day 21; after that, it returned to the same level of conditioning score as the respective saline control (SAL) group. The post hoc analyses revealed that TNJ significantly reduced the conditioning scores on Days 15 to 19. Similarly, the acamprosatetreated $(300 \mathrm{mg} / \mathrm{kg}$ bw, p.o.) animals showed a significant reduction in conditioning scores on extinction days (Day 15 to Day 19).

The effect of TNJ and ACAM on the rewarding prop- 


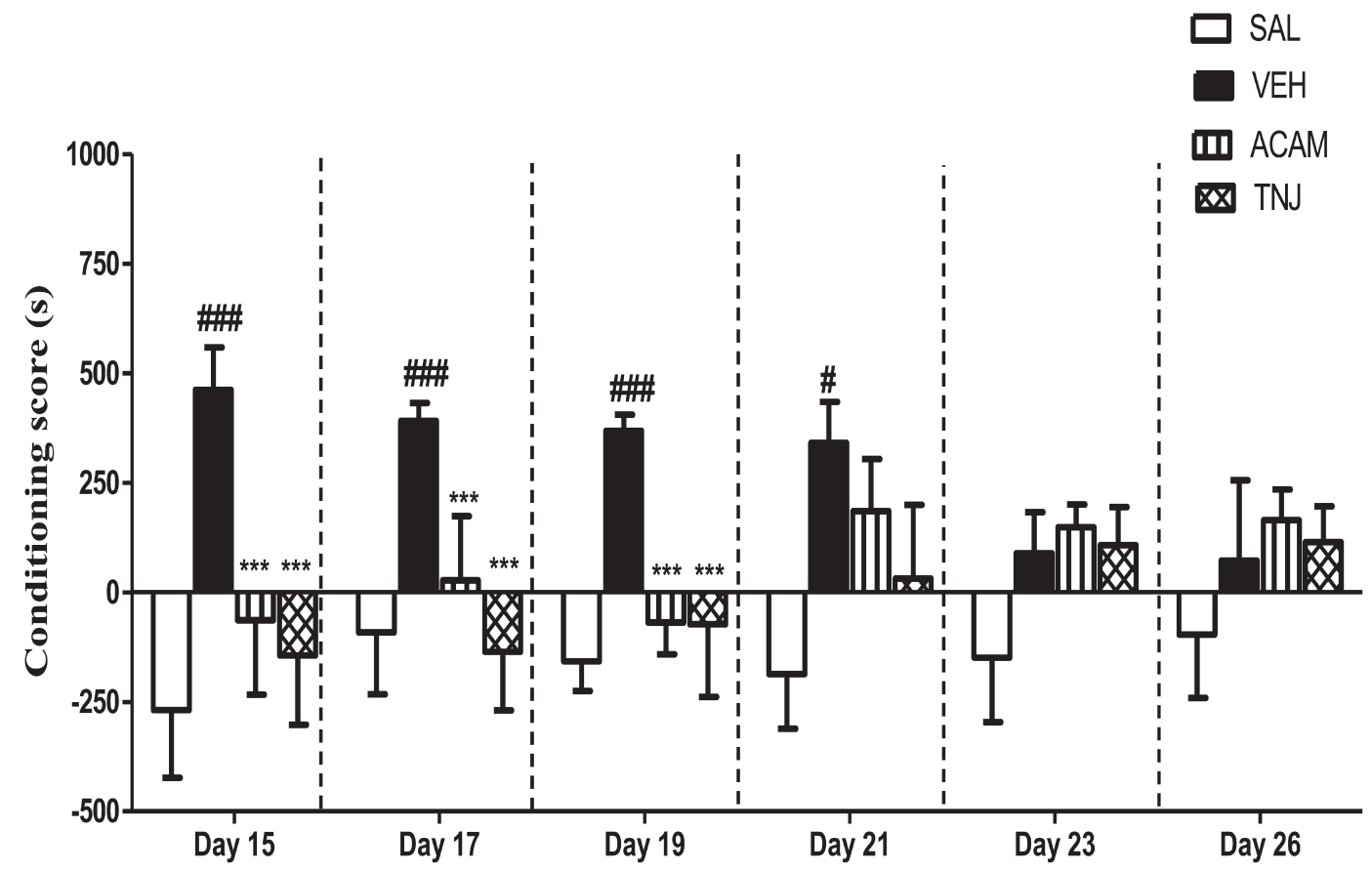

Fig. 3. Effect of TNJ and ACAM on the extinction of ethanol CPP in mice. Data are expressed as the mean difference between the times spent in the compartment paired with ethanol and the times spent in the compartment paired with saline ( $\mathrm{n}=7-9 /$ group). There were significant differences $(\# P<0.05$, \#\#\# $P<0.001)$ compared with saline control (SAL) group and compared with the vehicle control (VEH) group $\left({ }^{*} P<0.05, * * * P<0.001\right)$; when not indicated, the differences were not statistically significant.

erties of ethanol on reinstatement (Day 28) of ethanol CPP is shown in Fig. 4. The ANOVA results revealed significant effects of group $[\mathrm{F}(3,53)=10.04 ; P<0.001]$ and group $\times$ trial interaction $[\mathrm{F}(3,53)=3.287 ; P<0.05]$. The Bonferroni test revealed that the conditioning score of the vehicle-treated group on the reinstatement (Day 28 ) was significantly $(P<0.05)$ increased when compared with before reinstatement (Day 26). However, the conditioning scores on the reinstatement day were not altered in the TNJ- and ACAM-treated groups, which implies that TNJ and ACAM had anticraving effects on reinstatement of ethanol CPP.

\section{Discussion}

Despite the many reports published on noni, only a few neuropharmacological activities have been reported in the literature. Younos et al. (1990) demonstrated the sedative and analgesic activities of noni root extracts in mice and postulated the involvement of a central opioid receptor mechanism [39]. Kalandakanond et al. (2004) reported the anxiolytic activity of noni juice in rats in a study in which the authors compared the anxiolytic ef- fects of 15 or 30 days treatment with noni juices obtained from different sources, French Polynesia (Tahitian Noni Juice ${ }^{\circledR}$ ) and Thailand (Siam Noni Juice ${ }^{\circledR}$ ). The results of their study revealed the similar efficacies of both brands of noni juice at both time points, which were comparable with the efficacy of the reference drug, diazepam. Additionally, a 30-day treatment with both brands of noni juice did not significantly alter daily food consumption, body weight gain, and biochemical parameters related to liver and kidney functions [17]. These results confirmed the safety of noni juice in subacute treatment for 30 days. Recently, noni juice has been reported to have nootropic activity in stress-induced cognitively impaired mice using the Morris water maze (MWM) test [24].

Taking into consideration this brief summary of the neuropharmacological activities of noni juice reported in the literature, this study adds a new possible therapeutic benefit of noni juice with respect to alcohol dependence. The present study examined the effect of noni juice (TNJ) on the rewarding properties of ethanol using the CPP test in mice. Its results demonstrated that consumption of noni juice, TNJ, as a source of drinking 


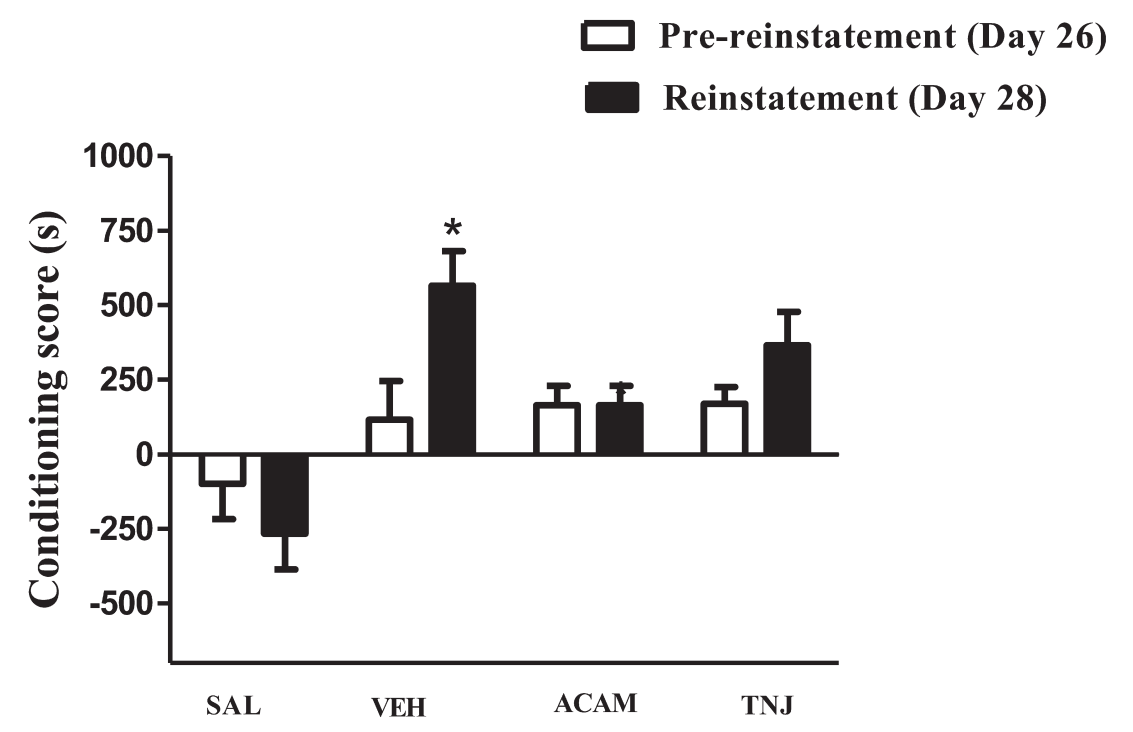

Fig. 4. Effect of TNJ and ACAM on low-dose ethanol-priming reinstatement of CPP in mice. Data are expressed as the mean difference between the times spent in the compartment paired with ethanol and the times spent in the compartment paired with saline $(n=7-$ $9 /$ group). There was a significant difference $(* P<0.01)$ between before and after reinstatement; when not indicated, the differences were not statistically significant.

water significantly alleviated the ethanol-seeking behavior in mice. Similarly, the reference drug ACAM (300 $\mathrm{mg} / \mathrm{kg}$ bw, p.o.) significantly attenuated the ethanolseeking behavior, which is consistent with a previously published report [22].

The amount of oral ethanol consumption in rodents provides a reliable index of ethanol's rewarding and reinforcing properties [14]. However, various factors such as genetic and environmental vulnerability, anxiety, novelty-seeking behavior, and the taste of ethanol may limit oral consumption of ethanol $[6,30]$. For instance, C57BL/6J mice (a strain with typically high ethanol consumption) exhibited weaker CPPs as compared with other inbred and mutant mice [14]. Other studies established ethanol CPP by simple alteration of the route of administration, the time of dose administration, or the cue paired with ethanol $[5,8,9]$.

Addiction is a persistent brain disease that occurs in episodes. Ethanol and other drugs of abuse exert their rewarding effects through activation of the dopaminergic system. Certain brain areas like the ventral tegmental area (VTA), nucleus accumbens, amygdala, and locus coeruleus and their connections inside the midbrain play a vital role in dopaminergic neurotransmission $[1,11]$. Ethanol stimulates DA release in the nucleus accumbens, which likely represents the neurobiological substrate for reward [26]. Eating (e.g., sweets), sexual behavior, and even gambling increases intra-synaptic levels of dopamine (DA) in certain brain areas, especially the nucleus accumbens [13]. Addicted users of ethanol showed a decreased density of $D_{2}$ receptors in the ventral striatum that persisted long after detoxification [13]. Interestingly, administration of $\mathrm{D}_{2}$ receptor antagonists was reported to reduce ethanol self-administration [12]. Thus it could be postulated that drugs having neuromodulatory effects on the dopaminergic system could be effective in the treatment of drug addiction.

Kalandakanond-Thongsong and Charoenphandhu (2012) reported that noni juice ( $1 \mathrm{ml} /$ day for 15 days) significantly reduced neurotransmitters, including noradrenaline in the amygdala and the hippocampus, 5-HT in the amygdala, and dopamine metabolites in the rat brain, such as DOPAC in the hippocampus and the substantia nigra and HVA in the substantia nigra [18]. In our earlier report, pretreatment with noni juice (TNJ) in drinking water for 7 and 21 days at 30, 50, and $100 \%$ $\mathrm{v} / \mathrm{v}$ significantly attenuated apomorphine-induced climbing behavior dose dependently in mice and demonstrated the antidopaminergic effect of the noni juice (TNJ) [29]. Therefore, it can be suggested that the antidopaminergic activity of noni juice could be involved in the attenuation of the rewarding effects of ethanol in the mouse CPP test. However, further mechanistic studies in this direction are warranted to unravel the actual 
mechanism of action of noni in treatment of alcohol dependence.

Furthermore, drugs that affect the motor activity of animals can influence CPP results. However, Pachauri et al. (2013) demonstrated that there was no significant difference in spontaneous locomotor activity in mice treated with a noni fruit extract [28]. Similarly, rats treated with noni juice orally for 15 days exhibited no alteration in motor activity [17]. It therefore seems that the effects of noni in the current CPP results cannot easily be accounted for by drug-induced changes in the subjects' motor activity.

Drugs that alter cognitive function (e.g., memory or attention) might also be expected to alter CPP data independent of their effects on reward. For example, NMethyl-D-aspartate (NMDA) receptor antagonists (MK801 and memantine) blocked the development and expression of conditioned place preferences induced by rewarding drugs such as morphine without any interaction in the reward pathways but instead by simply affecting cognitive function [1,31]. Recently, Pachauri et al. (2012) demonstrated a nootropic effect of Morinda citrifolia fruit in which fruit extract significantly reversed scopolamine-induced memory impairment in mice [27]. Likewise, in another report, an ethyl acetate extract of noni fruit prevented beta-amyloid (25-35)-induced cognitive dysfunction in mice [23]. In addition, administration of noni fruit juice protected brains from stress-induced impairment of cognitive function [24]. Given these results, it seems unlikely that the observed attenuation of ethanol CPP by TNJ in the current study can be accounted for by drug-induced memory impairment.

It has been well documented that reexposure to addictive substances and their related stimuli can reinstate the craving for a particular addictive substance [38]. In the present study, a low-dose of ethanol $(0.4 \mathrm{~g} / \mathrm{kg}$ bw, p.o.) priming in ethanol-extinguished animals significantly reinstated ethanol seeking in the CPP test. However, a similar reinstatement of ethanol CPP did not occur in TNJ- and ACAM-treated mice. This indicated the anticraving property of TNJ in the reinstatement of ethanol $\mathrm{CPP}$ in mice. In conclusion, we report for the first time that TNJ is effective in preventing ethanol seeking in the different phases of CPP in mice. Further clinical studies using noni fruit juice are warranted to support the present preclinical findings and to treat alcohol dependence.

\section{Conflict of Interests}

The authors declare that they have no conflicts of interest.

\section{Acknowledgments}

This study was supported by University of Malaya Research grants [RG495-13HTM and PG023-2014B] and an HIR MOHE grant [UM.C/625/1/HIR/MOHE/ MED/05 (H-20001-E000088)].

\section{References}

1. Aguilar, M.A., Manzanedo, C., Do Couto, B.R., RodríguezArias, M., and Miñarro, J. 2009. Memantine blocks sensitization to the rewarding effects of morphine. Brain Res. 1288: 95-104. [Medline] [CrossRef]

2. Camí, J. and Farré, M. 2003. Drug addiction. N. Engl. J. Med. 349: 975-986. [Medline] [CrossRef]

3. Center for Substance Abuse TreatmentIncorporating Alcohol Pharmacotherapies Into Medical Practice. 2009, Treatment Improvement Protocol (TIP) Series 49. HHS Publication No. (SMA) 09-4380. Rockville, MD: Substance Abuse and Mental Health Services Administration.

4. Chan-Blanco, Y., Vaillan, F., Perez, A.M., Reynes, M., Brillouet, J., and Brat, P. 2006. The Noni Fruit (Morinda citrifolia L.), A Review of Agricultural Research, Nutritional and Therapeutic Properties. J. Food Compos. Anal. 19: 645-654. [CrossRef]

5. Ciccocioppo, R., Panocka, I., Froldi, R., Quitadamo, E., and Massi, M. 1999. Ethanol induces conditioned place preference in genetically selected alcohol-preferring rats. Psychopharmacology (Berl.) 141: 235-241. [Medline] [CrossRef]

6. Cloninger, C.R., Sigvardsson, S., and Bohman, M. 1988. Childhood personality predicts alcohol abuse in young adults. Alcohol. Clin. Exp. Res. 12: 494-505. [Medline] [CrossRef]

7. Cunningham, C.L. 1995. Localization of genes influencing ethanol-induced conditioned place preference and locomotor activity in BXD recombinant inbred mice. Psychopharmacology (Berl.) 120: 28-41. [Medline] [CrossRef]

8. Cunningham, C.L. and Henderson, C.M. 2000. Ethanol-induced conditioned place aversion in mice. Behav. Pharmacol. 11: 591-602. [Medline] [CrossRef]

9. Cunningham, C.L., Clemans, J.M., and Fidler, T.L. 2002. Injection timing determines whether intragastric ethanol produces conditioned place preference or aversion in mice. Pharmacol. Biochem. Behav. 72: 659-668. [Medline] [CrossRef]

10. Dahchour, A. and De Witte, P. 2000. Ethanol and amino acids in the central nervous system: assessment of the pharmacological actions of acamprosate. Prog. Neurobiol. 60: 343-362. [Medline] [CrossRef]

11. Davis, M. and Myers, K.M. 2002. The role of glutamate and gamma-aminobutyric acid in fear extinction: clinical impli- 
cations for exposure therapy. Biol. Psychiatry 52: 998-1007. [Medline] [CrossRef]

12. Eiler, W.J.A. 2nd. and June, H.L. 2007. Blockade of GABA(A) receptors within the extended amygdala attenuates $\mathrm{D}(2)$ regulation of alcohol-motivated behaviors in the ventral tegmental area of alcohol-preferring (P) rats. Neuropharmacology 52: 1570-1579. [Medline] [CrossRef]

13. Goodman, A. 2008. Neurobiology of addiction. An integrative review. Biochem. Pharmacol. 75: 266-322. [Medline] [CrossRef]

14. Green, A.S. and Grahame, N.J. 2008. Ethanol drinking in rodents: is free-choice drinking related to the reinforcing effects of ethanol? Alcohol 42: 1-11. [Medline] [CrossRef]

15. Institute for Laboratory Animal Research Guide for the care and use of laboratory animals, 8th ed. Washington (DC): National Academies Press (2011).

16. Johnson, B.A. and Ait-Daoud, N. 2000. Neuropharmacological treatments for alcoholism: scientific basis and clinical findings. Psychopharmacology (Berl.) 149: 327-344. [Medline] [CrossRef]

17. Kalandakanond, S., Pandaranandaga, J., Komolvanich, S., and Poonyachoti, S. 2004. The anxiolytic effect of Noni (Morinda citrifolia L.). Thai J. Pharmacol. 26: 105-112.

18. Kalandakanond-Thongsong, S. and Charoenphandhu, J. 2012. Anxiolytic-like Effects of Noni juice (Morinda citrifolia L.) on the Respective Changes of Neurotransmitters in Rat Brain in the Elevated Plus-maze Test. Thai J. Vet. Med. 42: $275-280$.

19. Kuzmin, A., Sandin, J., Terenius, L., and Ogren, S.O. 2003. Acquisition, expression, and reinstatement of ethanol-induced conditioned place preference in mice: effects of opioid receptor-like 1 receptor agonists and naloxone. J. Pharmacol. Exp. Ther. 304: 310-318. [Medline] [CrossRef]

20. Lu, L., Liu, Y., Zhu, W., Shi, J., Liu, Y., Ling, W., and Kosten, T.R. 2009. Traditional medicine in the treatment of drug addiction. Am. J. Drug Alcohol Abuse 35: 1-11. [Medline] [CrossRef]

21. Mattioli, L., Titomanlio, F., and Perfumi, M. 2012. Effects of a Rhodiola rosea L. extract on the acquisition, expression, extinction, and reinstatement of morphine-induced conditioned place preference in mice. Psychopharmacology (Berl.) 221: 183-193. [Medline] [CrossRef]

22. McGeehan, A.J. and Olive, M.F. 2003. The anti-relapse compound acamprosate inhibits the development of a conditioned place preference to ethanol and cocaine but not morphine. Br. J. Pharmacol. 138: 9-12. [Medline] [CrossRef]

23. Muralidharan, P., Kumar, V.R., and Balamurugan, G. 2010. Protective effect of Morinda citrifolia fruits on beta-amyloid (25-35) induced cognitive dysfunction in mice: an experimental and biochemical study. Phytother. Res. 24: 252-258 10.1002/ptr.2922. [Medline]

24. Muto, J., Hosung, L., Uwaya, A., Isami, F., Ohno, M., and Mikami, T. 2010. Morinda citrifolia fruit reduces stressinduced impairment of cognitive function accompanied by vasculature improvement in mice. Physiol. Behav. 101: 211217. [Medline] [CrossRef]

25. Narasingam, M., Pandy, V., and Mohamed, Z. 2016. Noni (Morinda citrifolia L.) fruit extract attenuates the rewarding effect of heroin in conditioned place preference but not withdrawal in rodents. Exp. Anim. 65: 157-164. [Medline] [CrossRef]

26. Nevo, I. and Hamon, M. 1995. Neurotransmitter and neuromodulatory mechanisms involved in alcohol abuse and alcoholism. Neurochem. Int. 26: 305-336, discussion 337-342. [Medline] [CrossRef]

27. Pachauri, S.D., Tota, S., Khandelwal, K., Verma, P.R., Nath, C., Hanif, K., Shukla, R., Saxena, J.K., and Dwivedi, A.K. 2012. Protective effect of fruits of Morinda citrifolia L. on scopolamine induced memory impairment in mice: a behavioral, biochemical and cerebral blood flow study. J. Ethnopharmacol. 139: 34-41. [Medline] [CrossRef]

28. Pachauri, S.D., Verma, P.R., Dwivedi, A.K., Tota, S., Khandelwal, K., Saxena, J.K., and Nath, C. 2013. Ameliorative effect of Noni fruit extract on streptozotocin-induced memory impairment in mice. Behav. Pharmacol. 24: 307-319. [Medline] [CrossRef]

29. Pandy, V., Narasingam, M., and Mohamed, Z. 2012. Antipsychotic-like activity of noni (Morinda citrifolia Linn.) in mice. BMC Complement. Altern. Med. 12: 186. [Medline] [CrossRef]

30. Pohorecky, L.A. 1991. Stress and alcohol interaction: an update of human research. Alcohol. Clin. Exp. Res. 15: 438459. [Medline] [CrossRef]

31. Ribeiro Do Couto, B., Aguilar, M.A., Manzanedo, C., Rodríguez-Arias, M., and Miñarro, J. 2004. Effects of NMDA receptor antagonists (MK-801 and memantine) on the acquisition of morphine-induced conditioned place preference in mice. Prog. Neuropsychopharmacol. Biol. Psychiatry 28: 1035-1043. [Medline] [CrossRef]

32. Samoylenko, V., Zhao, J., Dunbar, D.C., Khan, I.A., Rushing, J.W., and Muhammad, I. 2006. New constituents from noni (Morinda citrifolia) fruit juice. J. Agric. Food Chem. 54: 6398-6402. [Medline] [CrossRef]

33. Singh, D.R. and Rai, R.B. 2007. Morinda citrifolia Linn an important fruit tree of Andaman and Nicobar Islands. Indian J. Nat. Prod. Resour. 6: 62-65.

34. Spanagel, R. and Zieglgänsberger, W. 1997. Anti-craving compounds for ethanol: new pharmacological tools to study addictive processes. Trends Pharmacol. Sci. 18: 54-59. [Medline] [CrossRef]

35. Tzschentke, T.M. 2007. Measuring reward with the conditioned place preference (CPP) paradigm: update of the last decade. Addict. Biol. 12: 227-462. [Medline] [CrossRef]

36. USPTO, Patent Full-Text and Image DatabasePatents (Morinda citrifolia). 2015 Retrieved July 31, 2015 from the World Wide Web: http://patft.uspto.gov/netacgi/nph.

37. Wang, M.Y., West, B.J., Jensen, C.J., Nowicki, D., Su, C., Palu, A.K., and Anderson, G. 2002. Morinda citrifolia (Noni): a literature review and recent advances in Noni research. Acta Pharmacol. Sin. 23: 1127-1141. [Medline]

38. Weiss, F. 2005. Neurobiology of craving, conditioned reward and relapse. Curr. Opin. Pharmacol. 5: 9-19. [Medline] [CrossRef]

39. Younos, C., Rolland, A., Fleurentin, J., Lanhers, M.C., Misslin, R., and Mortier, F. 1990. Analgesic and behavioural effects of Morinda citrifolia. Planta Med. 56: 430-434. [Medline] [CrossRef] 